\title{
Virtue Epistemologies and Epistemic Vice
}

\author{
By Eric Kraemer*
}

\begin{abstract}
While virtue epistemologists agree that knowledge consists in having beliefs appropriately formed in accordance with epistemic virtue, they disagree regarding what constitutes an epistemic virtue. Some take epistemic virtue to be a character trait. Others take epistemic virtues to be stable naturalistic dispositions which reliably produce true beliefs. There are also other virtue epistemologists who combine character traits and stable naturalistic dispositions into a "mixed" theory. All three focus exclusively on epistemic virtues, traits that lead cognizers to truth. But, the topic of epistemic vice is typically ignored. In this paper after arguing for the importance of accounting for epistemic vice, I consider dual systems theory, drawing a parallel with Ernest Sosa's distinction between two kinds of knowledge. I argue that information supporting dual systems theory helps explain two different kinds of epistemic vice. After pointing out important advantages for including both kinds of vice in virtue epistemology and showing how virtue epistemologies can be modified to accommodate epistemic vice, I conclude by suggesting that consideration of epistemic vice favors mixed theories of virtue epistemology.
\end{abstract}

\section{Introduction}

In his dialogue, The Theatetus, Plato asks the fundamental question regarding knowledge: how does it differ from mere true opinion? Most discussion since Plato attempts to isolate a special feature of the justification or evidence possessed by the knower but lacked by the one with mere true opinion. Historically the debate has raged between those, beginning with Aristotle, who argue for special beliefs to serve as foundations for other beliefs, and their opponents who argue that coherence relations between beliefs are required. Some who now find these approaches unrewarding turn instead to trying to isolate relevant features of the knower (virtues) which distinguish her from the non-knower (Sosa, 1980).

While virtue epistemologists agree that knowledge consists in having beliefs appropriately formed in accordance with epistemic virtue, they disagree regarding what constitutes an epistemic virtue. Some, virtue responsibilists, take epistemic virtue to be a character trait (such as intellectual courage), following the traditional Aristotelian conception of the moral virtues. (Montmarquet, 1993; Zagzebski, 1996). Others, virtue reliabilists, take

*Professor, University of Wisconsin-La Crosse, USA. 
epistemic virtues to be stable naturalistic dispositions which reliably produce true beliefs, such as proper perceptual practices (Sosa, 2009). There are also other virtue epistemologists who combine character traits and stable naturalistic dispositions into a "mixed" theory (Greco, 2000; 2010). All three versions of virtue epistemology focus almost exclusively on the epistemic virtues, that is, on traits that lead cognizers to truth.

But, since virtue epistemology is typically understood as analogous to virtue ethics, it is also reasonable to explore the potential role of epistemic vice in virtue epistemology. However, this topic is typically ignored by virtue epistemologists. It seems to be tacitly assumed by virtue epistemologists that one only need be concerned with epistemic virtues, not with epistemic vices. Perhaps this assumption is based upon consideration only two sorts of cases: those in which the cognizer possesses sufficient epistemic virtue versus those in which sufficient epistemic virtue is lacking. In the former case virtue epistemologists will claim knowledge is present and in the latter they will assert knowledge is absent. Were these the only two sorts of cases one needed to consider, it would be easy to explain why virtue epistemologists have ignored epistemic vices. But, what should the virtue epistemologist say about a case in which both significant epistemic virtue and significant epistemic vice are present? It would seem that the presence of significant epistemic vice would undermine any claim to knowledge provided by the presence of epistemic virtue.

The worry concerning epistemic vice assumes a category of human traits we can clearly recognize as epistemic vices. But, what are they and how might we identify them? Examining contemporary experimental cognitive science literature reveals both wide-spread natural character-traits and naturally occurring patterns of information processing that regularly lead the cognizer into error. It is these traits, which function with the opposite effect of the epistemic virtues but which have the added meretricious feature of appearing to those possessing them as though proper epistemic processing is occurring just as it should that I will call "epistemic vices". The disturbing concern that cognitive research reveals regarding these traits is that even careful epistemic appraisers are susceptible to them. While many ways in which human nature can distort judgment have been recognized since ancient times, recent cognitive science research reveals humans to be much worse off than previously imagined. There is persuasive evidence that humans are particularly inept at estimating their ability for objective self-evaluations, and are easily manipulated by various environmental factors into holding inaccurate beliefs both about themselves, others and the situations in which they find themselves.

In this paper after motiving the need for virtue epistemologies of both naturalist and non-naturalist inclinations to take epistemic vices seriously, I consider dual systems theory, drawing a parallel with Ernest Sosa's distinction between two kinds of knowledge: animal and reflective. I argue that information supporting dual systems theory helps explain two different kinds of epistemic vice. After pointing out important advantages for including these 
two kinds of vice in virtue epistemology, I conclude by suggesting that consideration of epistemic vice favors mixed theories over their competitors.

\section{Motivating the Need to Recognize Epistemic Vices}

Imagine a world consisting of well-designed cognizers, except better designed in the following sense. Instead of being susceptible to forming erroneous judgments, these cognizers are capable of forming accurate judgments based on information they receive within the parameters for which their cognizing faculties were designed. For example, assuming these cognizers were standardly designed for 20/20 vision, these cognizers could only form judgments regarding objects appropriately within the 20/20 parameter; for any information not within the parameter the cognizer would not form a judgment but, on entertaining a belief about the information, would immediately suspend judgment until better information was available. Imagine further the same held for the other senses such that an immediate suspension of belief occurred whenever any information came forward that could not be accurately processed. Imagine further that with respect to logical and mathematical reasoning the same held as well: one only made those inferences which were obvious in light of in-built principles, and inference that was not obvious was immediately identified as such and would either be subjected to further investigation or shelved. In such a world there would be no need for anything but virtuous epistemic processes to account for the operation of cognizers, since the processes would contain within their operation the necessary protections to prevent error from occurring. There would be no need to think that any vicious epistemic processes existed, only some processes which were perhaps more limited than one might have wanted. This parallels how we imagine computers being designed, namely to compute only certain specific problems according to specific programs installed within the computer using only very specific data. This is perhaps the view of traditional theistic philosophers who hold that God designed humans to be able to compute accurate knowledge. As a result of the Fall, however, significant cognitive disorder has set in which explains current flaws in our daily cognitive operations (see Plantinga, 2011).

In such a world we would only need to know that the virtues had been built into the design in order to trust judgments formed on the basis of that design. But this is not the world we inhabit. According to current experimental data humans constantly overreach their design limits. But the nature and extent of the over-reach is not widely appreciated. The problem of accounting for overreach is one important reason why any virtue epistemology which limits itself only to discussion of virtues will ultimately be unable to account adequately for both human successes and failures with respect to acquiring knowledge. Even if one accepts the view that humans were designed, we still need to understand the flaws in the current design if we are to account for knowledge within the design framework. 
Consider, on the other hand, the evolutionary perspective. On this view epistemic virtues and vices are not products of supernatural design, but rather consequences of non-directed evolutionary processes that result in the formation of complex mechanisms tending regularly to get many beliefs right much of the time. This impressive degree of accuracy is standardly explained in terms of survival and evolutionary success. The fact that humans can learn interesting things about the world and pass them on to their descendants is typically cited as explaining how much accuracy is selected for. However, it must also be admitted that humans also tend regularly get a significant number of other kinds of beliefs mostly wrong. The important task for those who hold the evolutionary perspective is to account for these differences with respect to human accuracy. But, if we limit our considerations to epistemic virtue and ignore epistemic vice, it is not clear how this task is to be accomplished.

Thus, whether one adopts the design framework or the evolutionary perspective, since neither approach rules out the many different kinds of errors in thinking that we find all humans committing, it is important to try to determine what kinds of natural processing work well for us and which do not. Consider another parallel with ethics. If ethical theorists only concentrated on good but never on evil, then we would regard their accounts as inadequate and truncated. The Good is that towards which we should all strive. But, it is widely recognized that to do so we must also seriously consider good's opposite, evil, and what leads some to engage in evil. Similarly, we must also ask epistemologists to become experts regarding those sorts of error to which humans are actually prone if they are to understand how to avoid it. So how are we to identify these errors? Let us turn to experimental psychology.

\section{Dual Systems Theory, Two Kinds of Knowledge, and Cognitive Illusions}

One view that receives significant support from experimental psychologists is "Dual Systems Theory". According to this view we engage in two different kinds of thought. Daniel Kahneman (2011) adopts the labels, System 1 and System 2, for these two systems which he characterizes as follows:

System 1 operates automatically and quickly, with little or no effort and no sense of voluntary control.

System 2 allocates attention to the effortful mental activities that demand it, including complex computations. The operations of System 2 are often associated with the subjective experience of agency, choice, and concentration (pp. 20-21).

According to Kahneman when we think of ourselves, we think in terms of System 2, which he calls "the conscious, reasoning self that has beliefs, makes choices, and decides what to think about and what to do;" but, he claims, 
System 1 in fact originates the "impressions and feelings that are the main sources of the explicit beliefs and deliberate choices of System 2".

Kahneman provides numerous examples of activities associated with both systems. System 1 activities include the following: (1) Detect that one object is more distant than another; (2) Orient to the source of a sudden sound, (3) Make a "disgust face" when shown a horrible picture; (4) Answer to " $2+2=$ ?"; and (5) Drive a car on an empty road. These cognitive activities are characterized by a certain automaticity or lack of effort. By contrast, the varied operations of System 2 have the common features of requiring attention and being "disrupted" when attention is withdrawn: As examples Kahneman provides the following: (1) Brace for the starter gun in a race; (2) Focus attention on the clown in the circus; (3) Search memory to identify a surprising sound; (4) Count the occurrences of the letter $a$ in a page of text; and (5) Check the validity of a complex logical argument. These examples, in contrast, all involve more concentration, attention, than those cited for System 1.

Ii is instructive to compare these two psychological systems with Ernest Sosa's framework for kinds of knowledge. Sosa refers to two kinds of knowledge: Animal Knowledge and Reflective Knowledge. The difference between the two kinds of knowledge depends on whether one has a perspective on one's knowing or not. Sosa has puts the distinction as follows:

We can more generally distinguish animal knowledge, which requires only that one track nature, on the one hand, and on the other reflective knowledge, which requires also awareness of how one knows, in a way that precludes the unreliability of one's faculties (Sosa, 2009, p. 199).

While Sosa's distinction has ancient roots, his claim that there are two kinds of knowledge would not have been accepted widely by ancient philosophers. Aristotle, for example, denies that there can be non-reflective knowledge; but, in De Anima (III: 12) he notes that the animal soul engages in calculation. Kahneman takes this automatic feature of thought to be the hallmark of System 1 thinking and Sosa makes it central to animal knowledge.

It is tempting to suppose that the dual-processing theorist's two systems of thinking and Sosa's two kinds of knowledge match up as follows: system 1 cogitations lead to animal beliefs which in the right circumstances lead to animal knowledge; system 2 cogitations lead to reflective beliefs which in the right circumstances lead to reflective knowledge. And, there certainly does seem to be significant overlap, even if there might not be a perfect correlation, between these two sets of dual categories. These two sets of dual categories do lead us to consider two different kinds of vice. Here's how.

Kahneman's discussion elaborates many ways in which experimental psychological research of the past several decades demonstrates prevalent and systematic failures to form true beliefs. These failures are due, first, to the limitations of System 1 in its initial belief formation processes, and second, to the limitations of System 2 to take adequate charge of the situation and the 
variety of evasive strategies it uses to bring cognitive peace, which instead contributes to significant cognitive errors. In addition to standard perceptual illusions, such as the Müller-Lyer illusion, Kahneman discusses many cognitive illusions that typically fool most human beings most of the time. Kahneman claims these illusions are the result of System 1 thinking manipulating System 2 thinking. These illusions include priming effects, inappropriate causal interpretations of chance events, substituting easier questions for harder ones, and confirmation biases. These tendencies are widespread dispositions that psychological research demonstrates occur regularly in human beings along with the successful cognitive activities listed above for System 1 and System 2 thought. The depressing lesson from this research is that we are often likely to be wrong--even when we think we have appropriately checked how we came to our beliefs--due to many in-built ways in which we tend to overstate our evidence, jump to conclusions, and be fooled by the way in which information is presented to us or by particular extraneous factors in our environment. The problem is these effects are wide-spread, systematic, and can even sneak up on the best prepared experimenter.

There are also more general features identified by Kahneman and others as problems. Kahneman speaks of the laziness of System 2 in terms of not wanting to work hard to examine the cognitive situations in which it finds itself. He also discusses the illusion of ease of coming up with answers to questions that are incorrect as fooling the cognizer into assuming greater accuracy than is in fact the case. Laziness and illusion of ease seem to be different sorts of epistemic vice to which humans are prone. So, let us now turn to a more systematic discussion of epistemic vice.

\section{Kinds of Epistemic Vices}

What kinds of epistemic vice are there? Let us begin our investigation of epistemic vice by considering the model of Aristotle's account of moral virtue in the Nichomachean Ethics. In this work Aristotle famously puts forward his Doctrine of the Golden Mean, according to which virtue consists in finding the proper mean between two extremes. This account of virtue also gives us an account of vice. Behaviors that are too extreme, either in terms of excess or deficiency, are regarded as vices. Vice consists in doing something too much or not enough. This account of vice is transferable to the epistemic realm. Consider for example the virtue of pattern recognition. Humans need to be proficient at pattern recognition in order to pick up important clues about what is happening in the world. Not adequately observing the color of traffic lights for a trained driver is a serious epistemic vice. On the other hand, spending too much effort trying to find patterns in areas where one has no good reason to suppose that patterns exist, also seems to be a serious epistemic vice. (Being an obsessive conspiracy theorist is an example of an excess to be avoided.) So, we can understand some epistemic vices as cognitive deficiencies and others as cognitive excesses with respect to a particular mean.But, even Aristotle admits 
that, while many ethical virtues (and vices) can be accounted for using the Doctrine of the Golden Mean, some activities, such as adultery, are simply wrong; it is just not appropriate to try to determine the correct number of acts of adultery to commit in the right way at the right time with the right person, etc. If we wish to continue to try to find parallels with epistemic vices and virtues, then there seem to be two, closely related further models of virtue and vice that need to be considered. First there are those states whose even minimal presence is regarded as a vice, for example cognitive hubris, perhaps, the conviction that one has special epistemic powers in a certain domain that one in fact lacks.

Second there are states whose simple absence is to be regarded as a vice. Here the visual example of color-blindness comes to mind. While some individuals are more color-blind than others and there are a number of different kinds of color-blindness, lacking color vision is an epistemic vice. We can generalize from these cases as follows.

Suppose we agree with Sosa regarding there being two kinds of knowledge: animal and reflective. First, it seems appropriate to note that certain epistemic vices with respect to reflective knowledge should be construed as what I will call Aristotelian vices: either deficiencies or excesses with respect to some mean. Thus, we might think of epistemic courage as a virtue, whose two corresponding two epistemic vices are epistemic timidity, being too scared to meet the epistemic challenges one faces in a particular situation, and epistemic rashness, being much too quick to jump to conclusions, to assume that one knows when does not.

Secondly, with respect to Animal Knowledge however, we need to look to another model of vice. Alasdair MacIntyre reminds us that among the ancient Greeks fleetness of foot was considered a virtue (MacIntyre, 1997, Chapter 2). Fleetness of foot is not appropriately construed as a mean between two extremes, but as a reliable ability to perform at a certain level required for success. Since this virtue comes from the Archaic period of the ancient Greeks, let us refer to this as an Archaic virtue. It seems that virtue reliabilists have this notion of virtue in mind. Given this account of virtue, a fitting corresponding archaic vice might be something like slowness-of-foot, which is a particular inability to perform at a required level of performance in order to achieve recognition and success. Thus, for virtue reliabilists, the sort of vice with which to be concerned is that of an ingrained process, some established epistemic trait of a cognizer, that fails to perform reliably to achieve correct cognitive outcomes.

There seem to be many such traits that are relatively easy to find. Consider, for example, the trait of mistaking the fallacy of affirming the consequent for modus ponens. This trait is one that a good course in logic and continued vigilance combined with the habit of always symbolizing the arguments one encounters should eliminate. But, its elimination requires considerable effort. More insidious, however, are the various framing effect problems, the many classic perceptual illusion cases, and priming cases, all of 
which seem to point to processes we are just not likely to be able to eliminate in the human population, or even completely within a single individual.

Similarly it seems that virtue responsibilists, those who think of virtue in terms of character, would probably have a very different conception of vice in mind when they consider the topic of epistemic vice. For virtue responsibilists the Aristotelian model of virtue and vice seems a much better fit. For the mixed virtue theorist, clearly both kinds of vices are relevant.

\section{The Significance of Epistemic Vices for Virtue Epistemologies}

The virtue epistemologist may still not be convinced. Suppose she poses the following challenge: You claim that there are, in addition to epistemic virtues, epistemic vices, and you claim that virtue epistemologies need to take account of them. But, why should we accept your claim? Why are the virtues insufficient? What additional epistemological roles require epistemic vices? Why is there a problem with simply maintaining that those who possess epistemic virtues have knowledge and those who lack them also lack knowledge?

In reply, first, it may be worth repeating a point made above, this time in the form of a more formal argument. Consider the following Argument from Epistemic Luck. Suppose someone, S, believes some claim, p. Suppose further that $\mathrm{p}$ is true and that there is some virtue $\mathrm{T}$ that connects $\mathrm{S}$ with $\mathrm{p}$. But, suppose further that one of the sustaining causes of S's believing that $p$ is one of the many persuasive cognitive illusions uncovered by cognitive scientists. Let us think of this illusion as a cognitive vice, $\mathrm{C}$. Even if $\mathrm{S}$ has a supplementary route to her belief that $\mathrm{p}$ that may involve an error-free process, there is still the question as to whether in this particular circumstance $\mathrm{S}$ really knows that $\mathrm{p}$ given that she is in fact connected to $\mathrm{p}$ via both $\mathrm{T}$ and $\mathrm{C}$. In this case we should say that the conjunction of $T$ and $C$ undermines the claim that $S$ knows that $p$. Even if we further suppose that $S$ would still believe that $p$ in the absence of $\mathrm{C}$, this is not enough to establish knowledge of $\mathrm{p}$. This is because it would also be the case that $S$ would still believe that $p$ in the absence of $T$. It is a simple matter of epistemic luck that both $\mathrm{T}$ and $\mathrm{C}$ hold for $\mathrm{S}$. Thus, since instances of epistemic luck are not cases of knowledge, $\mathrm{S}$ in this case lacks knowledge.

There are, in addition, further reasons for virtue epistemologists to revise their approach to incorporate epistemic vices. Here are a half dozen.

First, the analogy between virtue ethics and virtue epistemology makes much more sense if epistemic vices are explicitly acknowledged and taken into account. If the virtues are regarded as positive tendencies, the vices can be taken as negative tendencies, where positive tendencies are those, in the epistemic context, which promote the likelihood of the truth of a belief to be greater than .5 and negative tendencies, similarly, are those which promote the likelihood of the truth of a belief to be less than .5 (Compare Sosa, 2012). 
Second, the inclusion of epistemic vices presents a more complete account of how knowledge emerges out of the human condition, which is what virtue epistemology, in its various forms, is concerned to demonstrate. It is not just the case that humans are prone either to get things right or to engage in epistemically neutral activity. There are many typical human activities that, because of our psychological nature, almost certainly doom us to error. And, confronting how these tendencies are to be circumvented is an important aspect of understanding what is required for knowledge.

Third, the inclusion of epistemic vices makes clear which aspects of human psychological functioning need to be carefully examined by epistemologists. This inclusion also underscores the importance of epistemologists learning more about human psychology and the gullible tendencies we all have to accept certain, poorly-considered beliefs.

Fourth, discussion of epistemic vice should lead to a more adequate account of the normativity of knowledge claims. The negative effects of certain behaviors and traits are also important norms to consider, not just positive effects.

Fifth, the inclusion of epistemic vices makes it clear that virtue epistemologists, too, have a counter-part to the notion of defeat, a notion which plays a key role in justification and warrant-based epistemologies. Belief supported by epistemic virtue may be defeated by epistemic vice.

Sixth, the inclusion of the epistemic vices also enables us to account better for higher-order levels of knowledge, of our knowledge of our knowledge. Only by knowing different ways in which we can be deceived and by taking them into direct consideration in particular cases can we hope to obtain enough knowledge of the limits of how we know to engage in serious epistemology. Thus, there are significant epistemic reasons for incorporating epistemic vices into a virtue epistemology program. But, how might this be done?

\section{Integrating Vices and Virtue Epistemologies}

Let us now examine some current versions of virtue epistemology theories to see how the inclusion of epistemic vice might strengthen these theories. Consider Sosa's recent (2009) virtue reliabilism:

"A belief amounts to knowledge only if it is true and its correctness derives from its manifesting certain cognitive virtues of the subject, where nothing is a cognitive virtue unless it is a truth-conducive disposition" (ibid., p. 235).

Sosa's account needs to be augmented by adding the clause that the correctness of the belief also does not derive from its manifesting certain Archaic cognitive vices of the subject, where nothing is an Archaic cognitive vice unless it is a falsity-conducive disposition. With this addition Sosa's principle avoids the Problem of Epistemic Luck. 
Let us compare this approach with Zagzebski's (1996) virtue responsibilism:

"Knowledge is a state of belief arising out of acts of intellectual virtue."

For Zagzebski, an act of intellectual virtue is to be understood as an act motivated by intellectual virtue. Zagzebski, an Aristotelian with respect to virtue, recognizes that there can be conflict between competing virtues, and requires that:

"A justified belief, all things considered, is what a person with phronesis might believe in like circumstances" (ibid., pp. 270-271).

One objection to Zagzebski's view is that her account of justified belief may already be accommodating without explicit recognition the notion of Aristotelian intellectual vice by appealing to phronesis (practical wisdom). A second objection is that, given the factors cited above from the cognitive psychological literature, phronesis is not able to detect problematic cognitive illusions that undermine objective justification. Thus, Zagzebski's account would need to be modified to include what a person who is also not suffering from unnoticed Archaic vices might believe in like circumstances.

A third virtue epistemology example, from a mixed account, comes from John Greco (2000). Greco defines subjective justification in terms of Aristotelian virtues:

"S is subjectively justified in believing $\mathrm{p}$ if and only if S's believing $p$ results from the dispositions that $S$ manifests when $S$ is motivated to believe the truth" (ibid., p. 190).

One problem that arises for Greco's analysis is that one can be motivated to believe the truth by natural but illusory dispositions. It might be helpful to specify that no Aristotelian vices are also being manifested when $S$ is motivated to believe the truth.

Greco further provides an account of knowledge using Archaic virtues, claiming knowledge occurs only where there is both subjective justification and "as a result of this $\mathrm{S}$ is objectively reliable in believing $\mathrm{p}$ ". The additional problem Greco's second account faces is the Epistemic Luck Problem noted above, in which one can be both objectively reliable and non-reliable depending upon which dispositions one considers. One solution to this objection is to modify Greco's analysis to include the requirement that $\mathrm{S}$ is not objectively unreliable in believing that $\mathrm{p}$ due to the presence of certain Archaic vices.

Thus, we see that the addition of reference to either Archaic or Aristotelian vices, or both, enables defenders of various virtue-based epistemological 
theories to avoid problems raised by the many insidious cognitive illusions discovered by recent cognitive science.

\section{Conclusion}

What further moral should we draw from this discussion? Assuming two different kinds of epistemic vice, automatic Archaic vices and dispositionbased Aristotelian vices, it seems highly appropriate for both virtue reliabilists and virtue responsibilists to re-examine their monist approaches and reconsider advantages Mixed Theorists have in accommodating not only more epistemic virtues but also more epistemic vices. Virtue responsibilists are unable to account for the many ways in which specific dispositions to believe incorrectly appear to undermine the reliability of many knowledge claims in spite of our best efforts. And, virtue reliabilists are unable to account for general epistemic character traits, such as epistemic laziness and hubris, which affect one's overall status as a knower. Thus, a revised mixed virtue epistemology, one which attempts to deal with both sorts of virtues and vices appears better positioned to accommodate the interesting and disturbing results from cognitive psychological research regarding cognitive error.

\section{References}

Greco, J., 2000. Putting Skeptics in Their Place. New York: Cambridge University Press.

Greco, J., 2010. Achieving Knowledge. New York: Cambridge University Press.

Kahneman, D., 2011. Thinking Fast and Slow. New York: Farrar, Straus and Giroux.

MacIntyre, A., 1997. A Short History of Ethics. $2^{\text {nd }}$ Ed. Notre Dame: University of Notre Dame Press.

McKeon, R., 1968. The Basic Works of Aristotle. New York: Random House.

Montmarquet, J., 1993. Epistemic Virtue and Doxastic Responsibility. Lanham: Rowman \& Littlefield.

Plantinga, A., 2011. Where the Conflict Really Lies: Science, Religion and Naturalism. Oxford: Oxford University Press.

Sosa, E., 1980. The Raft and the Pyramid: Coherence versus Foundations in the Theory of Knowledge. Midwest Studies in Philosophy, 5, pp. 3-25.

Sosa, E., 2009. Reflective Knowledge. Oxford: Clarendon Press.

Sosa, E., 2012. Knowing Full Well. Princeton NJ: Princeton University Press.

Zagzebski, L., 1996. Virtues of the Mind. Cambridge: Cambridge University Press. 
